\title{
Certification and the American Phytopathological Society
}

The profession of plant pathology strives to improve the health and safety of the public through improved plant health systems. This includes the benefits afforded by well-managed urban landscapes and abundant food and fiber. However, the proud glow of the profession of plant pathology has dimmed over the past 20 years to the point that some members of the American Phytopathological Society (APS), the principal professional society of plant pathologists in the United States, are not sure what a plant pathologist should know or what a plant pathologist is responsible for (Phytopathology News 30:162). Without a unified, positive direction for the profession of plant pathology, we will see continued dissolution of academic plant pathology departments to departments such as microbiology, ecology, and plant science. We lament that the public doesn't understand who we are, and we seek ways to change that public perception.

Plant pathology can be divided into two major components: (i) the science of plant pathology, and (ii) the profession of plant pathology. The basic research discoveries that lead to the development of the scientific principles of plant pathology provide the foundation for the profession. The profession of plant pathology is the application of those scientific principles in production agriculture, forestry, and urban settings to benefit the public by safely reducing the negative impact of plant diseases.

In the past, there was little need for separation of these two components. The science and profession of plant pathology were tightly aligned, and both were provided by the government through university and USDA research and extension programs. More recently, however, the profession of plant pathology has grown more privatized. Services that used to be provided by extension directly to the farmer are now sometimes provided by agrochemical industry advisors and independent advisors.

The authors are members of the National Plant Pathology Board, which was authorized by APS Council in 1991 to provide scientific input to national policy-making processes.

Corresponding author: L. J. Stowell

E-mail: stowell@pace-ptri.com

Publication no. D-1998-0611-010
When the profession of plant pathology is managed by the government (extension), plant pathologists are selected based upon their qualifications as established by government guidelines. Today, many individuals who diagnose and recommend plant disease management and control procedures may or may not have the necessary qualifications (knowledge) to responsibly practice within the profession of plant pathology. If the APS is the steward of both the science and the profession of plant pathology, it is the responsibility of APS to identify for the public those individuals who have the qualifications necessary to practice plant pathology. The Certified Professional Plant Pathologist (CPPP) program was developed for this purpose. The CPPP program promotes the profession of plant pathology and identifies for the public those individuals who possess the qualifications needed to practice the profession of plant pathology.

While certification of professional plant pathologists is not the solution to our identity crisis, it is a significant step in solidifying our vision of the profession. As with the medical profession, there are many aspects of plant pathology that encompass specialization and research that are not strictly described by the certification of professionals.

Unfortunately, since its introduction in 1991, only a handful of people (fewer than 40) have been granted certification through the CPPP program. We believe the lack of interest in the program is largely due to lack of promotion and understanding of its purpose. There is no budget for development of promotional materials, and there is no direct short-term economic benefit to the APS to encourage certification. Many APS members do not perceive a positive personal value from certification because they are employed by universities or government agencies. Here, we provide some background on the CPPP program and recommended steps APS can take to promote the profession of plant pathology through a strong and effective professional certification program.

\section{Background}

The CPPP program is a cooperative effort of the American Society of Agronomy (ASA) and the APS. The program resides under administrative control of the ASA, and all economic liability is shouldered by the ASA. The president of the APS is responsible for recommending the members of the Plant Pathology Board, and these individuals are appointed by the president of the ASA. The guidelines for certification are under the control of the Plant Pathology Board, but they are approved by the ASA Council. The CPPP program is a membership service of the ASA.

APS members have been only slightly interested in certification, and only a single member of the APS Council has sought certification. We believe this lack of interest reflects the primarily academic and research focus of APS. The APS has not been very effective in recruiting members from the population of practicing plant pathologists. Based upon a 1997 survey, approximately $80 \%$ of the independent crop consultants provide fungicide recommendations to farmers (Independent Crop Consultant Survey, January 1997, Doane Agricultural Services Company, St. Louis, MO.). In a previous survey, Doane estimated that there are 3,511 independent crop consultants in the United States (Independent Crop Consultant Survey, 1993. Doane Agricultural Services Company, St. Louis, MO.). In addition to the independent crop consultants, the ASA CCA program currently registers more than 8,000 Certified Crop Advisors. Although the exact number of individuals who recommend plant disease management procedures and products is currently unknown, the count is significant.

The APS does not have a good vehicle for contacting plant pathologists in the private sector who are not already APS members. Moreover, APS does not offer many membership services that would attract private practitioners (industry representatives and private consultants). Those services would include advanced disease identification and management teach-ins, new technology sessions, and enhanced communication between private professionals and university researchers. How big is this potential membership opportunity? It depends upon the benefits a professional will gain through membership. This is a new opportunity for the APS. Does the APS need these private practitioners? If it is going to assume responsibility for stewardship of the profession of plant pathology, the answer is yes. Encouraging certification of qualified practitioners is both a responsibility and an opportunity for the APS. 


\section{The Role of Extension and APS}

During these times when extension has experienced continuous budget cuts, the CCA and CPPP programs offer significant opportunities for extension education. Coupled with national expertise offered by professional societies, such as the APS, extension might enter a new realm of advanced professional education targeted at satisfying the continuing education requirements of certified professionals. The APS can play a key role in organizing and delivering high quality workshops and teach-ins. In addition to on-site training, distance education programs might be developed and implemented using APSnet. This effort will also require close interaction between extension professionals and other APS members throughout the country. Extension participation will be a critical component to any professional plant pathologist training program. Applied training programs that do not effectively use extension may be perceived as a competitor to extension's current education efforts.

\section{Examination Standards}

The Certification Advisory Council (CAC) was formed in 1996 to help standardize the efforts of the many certification programs offered to agricultural and related professionals. This group is composed of representatives for each of the certification programs and a representative from the governing board of the sponsoring organization. The CAC has recommended that all professional certification programs use an examination-based certification standard. In other words, it doesn't matter if you received a degree in plant pathology: you must be able to meet a certain standard of knowledge. For plant pathology, the exams would be targeted at performance objectives determined by plant pathologists in various sectors (academic, extension, industry, private practice) under the direction of the APS. The details of this process are well known, and the performance objectives for several other certification programs are available to the APS for review. The cost of development of a standard national exam can be high, and grant funding may be needed to cover the expense.

The advantage of an examination standard is that people do not need a bachelor's, master's, or Ph.D. degree in plant pathology to become certified. They need to have the knowledge to pass the exam (similar to a Bar or Medical exam) and the proper professional work experience. For example, in addition to passing the exam, certification would only require 5 years of experience in plant pathology. For someone with an M.S. in plant pathology or a related field, only 3 years of professional experience would be required. For someone with a Ph.D., only 1 year would be required.

Undergraduate education programs might be modified so that students who want to pursue a career in plant pathology could acquire the knowledge to pass the CPPP examination. Even though there is a current shortage of students in plant pathology, there are many professionals currently practicing plant pathology. How are they being educated? How will future plant pathologist acquire the knowledge to responsibly practice plant pathology?

Since the development of the CPPP program, some departments of plant pathology have been merged with other agricultural science departments. There are fewer locations where someone can be trained and receive an undergraduate degree in plant pathology. Based upon the number of professionals providing plant disease related recommendations, there needs to be a vehicle for students to pursue a career in plant pathology when academic opportunities for attaining a plant pathology degree appear to be diminishing. A similar knowledge-based evaluation is used in the CCA program that has attracted many crop advisors throughout the country. The CPPP program will also allow many CCAs to document their expertise in plant pathology.

The American Phytopathological Society has the opportunity and obligation to take a leadership role in developing the profession of plant pathology. Without this leadership, the profession will continue to flounder and decline. Promoting certification will help the public understand our profession, and it will help members of the APS better understand what a plant pathologist does: our commitment to research and knowledge, our concern for public and environmental safety, and our ability to reduce losses in yield and quality caused by diseases of plants. Certification not only demonstrates to the public our concern for how our profession is practiced, it also provides a focus for discussion that may help unify plant pathologists who are now unsure if there is a profession of plant pathology. The APS can and should be at the focal point for fostering and facilitating that discussion.

The following recommendations describe the steps that are needed to effectively promote the profession of plant pathology through a strong and effective professional certification program.

1. Assess the value of certification to the APS by the year 2001 and provide a recommendation to continue or terminate certification efforts.
2. Assess the need for development of a national Plant Pathologist examination to replace the current credential-based certification system. Seek funding to support examination development if an examination standard is desired.

3. Empower a voting APS council member to represent Certified Professional members.

4. Establish a society general policies committee composed of APS members interested in certification and continuing education-not the plant pathology certification board.

5. Establish a budget within APS for promotion of certification and development of educational programs for Certified Professionals.

6. Assess the value of distance education programs developed by APS to serve Certified Professional Plant Pathologists and Certified Crop Advisors (8,000 CCAs today, with an estimated 20,000 by the year 2000).

7. Establish direct linkage with the Extension Committee and develop workshops and material to serve the needs of Certified Professional Plant Pathologists and also Certified Crop Advisors. Extension participation is critical.

L. J. Stowell

E-mail: stowell@pace-ptri.com

PACE Consulting

San Diego, CA 92109

J. Amador

Texas Agricultural Experiment Station

Weslaco, TX 78596

O. W. Barnett

Plant Pathology Department

North Carolina State University

Raleigh, NC 27695-7616

R. J. Cook

Departments of Plant Pathology and Crops \& Soils

Washington State University

Pullman, WA 99164-6430

D. E. Mathre

Plant Pathology Department

Montana State University

Bozeman, MT 59717

A. K. Vidaver

Plant Pathology Department

University of Nebraska

Lincoln, NE 68583-0722

S. A. Tolin

Plant Pathology, Physiology and Weed Science Department

VPI and State University

Blacksburg, VA 24061-0330 